\title{
On the Influence of Online Teaching on Educational Equity
}

\author{
Lyu Yiqi ${ }^{1}$ \\ ${ }^{1}$ School of Dalian University of foreign languages, Liaoning, Dalian 116044, China \\ ${ }^{*}$ Corresponding author. Email: lvyiqiyouxiang@163.com
}

\begin{abstract}
With the development of electronic information technology, online teaching has gradually come into people's view, whose popularity has been unwittingly promoted by the sudden outbreak of COVID-19. As this teaching form becomes more and more popular, some new problems also arise. Research shows that online teaching has advantages including flexible time, unlimited location and optimization of educational resources. Under the impact of a sudden coronavirus epidemic, online teaching is widely used because there is no need to be face-to-face as traditional teaching methods. What's more, this kind of involuntary use of new teaching form also brings new challenges to the realization of educational equity. The impact of online teaching form on educational equity is analyzed in this paper from the perspective of students, teachers and parents. Some suggestions have also been put forward.
\end{abstract}

Keywords: Online teaching, Online learning, coronavirus epidemic, course format, electronic equipment, Online teaching platform, distance education

\section{BACKGROUND}

In the era of big data, Internet plus has been gradually integrated into our daily life, in which more and more electronic objects are being implemented. School teaching is also gradually explored into electronic teaching. Entry through tablet computers is a great innovation. There is scale effect in distance education mode, which cannot be limited by space or time. Even if teachers and students are not in the same country or time zone, the class is not affected. There are two modes of electronic education: online teaching and excellent course recording. Many educational institutions and schools have begun to use this form of online teaching. Compared with recorded courses, realtime interaction can be achieved between teachers and students through online teaching. Without problems such as a poor network speed and equipment failures, it has a strong similarity with the traditional teaching form. Course recording is conducive to a wider spread of high-quality courses. Many famous teachers in famous schools can record their own online courses and make them into excellent courses, which are widely used as high-quality educational resources. Even if you can't go to these famous schools, you can also listen to their courses. This is the unprecedented convenience and benefits of online teaching.

There are many differences between the traditional teaching mode and the online teaching mode. First of all, for traditional education, the requirements for teaching conditions are low. Students can be taught just with a chalk and paper textbooks, tapes or other simple knowledge carriers, a blackboard, a few desks and chairs, which are important reasons why traditional classroom teaching can be continued and developed for hundreds of years. The high development of science and technology is the basis of online teaching, the premises of whose rise include the popularization and application of computers and multimedia network information technology in society. It integrates pictures, texts, sound and images, through which teaching activities can be carried out vividly. Therefore, it has higher requirements for the conditions of local network technology, students' family condition and economic affordability. In some remote and economically backward areas, the infrastructure is not in place and the economic conditions are poor, where there will be more difficulties in developing distance education and carrying out online teaching.

Secondly, the subject is different. The online teaching mode is a student-centered classroom teaching 
mode, whose main theoretical basis is the learning and teaching theory of constructivism, which holds that students are the main body of the learning process and active constructors of meaning. The acquisition of knowledge is not achieved through teaching, but through active meaning construction under certain circumstances, which requires students' initiative and enthusiasm in learning. The traditional classroom teaching mode is teacher-centered, whose main theoretical basis is Ausubel's learning and teaching theory in the second half of the $20^{\text {th }}$ century. Ausubel believes that the essence of meaningful learning is to establish a non-human and substantial connection between new knowledge represented by symbols and existing knowledge in learners' original cognitive structure. The so-called substantive connection refers to the equivalence of different words, that is to say, the connection is not literal. For example, when we learn 5 $+5+5=3 \times 5$, we can find that the result on both sides of the equation is 15 , so that we can understand this substantive connection as the same knowledge. As long as we understand its essence, we can understand it in any form. The so-called non-human connection refers to an internal connection rather than an arbitrary association or connection, which refers to the connection between new knowledge and related concepts in the original cognitive structure on a reasonable or logical basis. For example, when we learn a new word, because we don't understand phonetics, pinyin is used instead. At this time, the artificial connection is not meaningful learning. It must be emphasized in the essence of meaningful learning that only by truly connecting new knowledge with our existing knowledge can we call it meaningful learning. The teaching ability of teachers affects the learning effect of students to a certain extent. So there will also be higher requirements for teachers' abilities on all aspects.

The third is the differences among educational modes. The main elements of online teaching mode are teachers, students, teaching content, teaching media, support platforms for teaching and learning, etc. Teachers choose to teach online or record courses, and prepare lessons for what they need to teach, corresponding courseware as well as electronic teaching materials, etc., and they contact and interact with students through electronic teaching platforms. The courses can also be published in electronic platforms for students to watch at any time. Students connect to the course center through the computer network, on which they register, log in and choose the courses to study. In this process, the teachers' identity also changes from the dominant position of the classroom to the guidance of students' learning. The main elements of traditional teaching mode are teachers, students, teaching content and teaching media. Teachers choose teaching content according to the requirements of the syllabus, the characteristics and cognitive basis of students, and then spread it to students through traditional teaching methods, such as oral teaching, blackboard writing and so on. Students need to sit in the classroom and accept knowledge by listening to the teachers, taking notes and answering questions. In this process, teachers can get feedback from students and adjust the content of the class by observing students' expression, state and action, etc. Teachers are the center and the leading role of teaching activities as well as the imparter of knowledge, and students are receivers of knowledge. Media are tools for teaching, teaching materials are the content of teaching, syllabus is the outline of teaching, teaching plan is the plan of teaching, students' achievement is the reflection of teachers' level, and classroom is the stage for teachers to perform.

However, when online teaching became the only teaching method available during the epidemic period, many problems emerged. Online teaching needs the support of electronic equipment and network. Electronic devices such as computers, tablets and mobile phones, etc. are expensive, which cannot afford by everyone. Besides, online classes need one person and one machine. Maybe some families can afford a mobile phone and a computer. But for those families with more children, parents have to face the problem of purchasing corresponding electronic devices for each child, which virtually increases the financial burden of parents. Moreover, in terms of network, its construction in today's world is not perfect, which also has not covered all regions. For those children living in remote areas, if they can only be taught online, it is equivalent to cutting off the possibility of their education. If they can't receive education because they live in a place without network, then online education will become the biggest obstacle for them to get education, which undoubtedly brings great challenges to educational equity and also increases the difficulty in its realization. It is just a matter of equipment. For teachers, especially those who are older, such a new way of teaching has brought them professional crises. Under the influence of the epidemic, teachers who are used to traditional teaching methods are forced to use unfamiliar teaching methods. If teachers cannot learn how to teach online, they will face the crisis of unemployment, which is not fair to them. Similarly, teachers may lose their job because they live in areas where there is no Internet or they cannot afford to pay for classroom equipment. The above are influences during the epidemic with only a single form of online teaching that can be used.

\subsection{Literature Review}

\subsubsection{The Definition of Educational Equity}

People often confuse the concept of identity and equality. Equality refers to the same degree of having a 
certain quality or attribute compared with others. Of course, it should not be equated with strict egalitarianism, that is, treating everyone in exactly the same way regardless of personal or cultural differences. As for educational equality, the implementation is talked about more. Here, it is necessary to reemphasize the equality defined in this article. Kathleen and John strictly defined such equality as a "conditional equality". We suppose that the equality is a kind of state on condition. Friedman and others believe that efficiency must be pursued in both social and educational development, which inevitably produces various inequalities. But that does not mean that we cannot pursue equality, which should be dynamic and will change with different conditions. It is not a result of eternal stillness, but a process of eternal changes and a state of continuous efforts towards fairness. Trying to achieve a relative equality by various means, what we need to make sure is that it is moving in a direction of becoming fair, no matter what its trajectory is. As long as it is moving in such a direction, it is a state of equality that we are talking about. At the same time, it is easy to confuse the concept of equality of conditions with that of results. First of all, the conditions advocated by this kind of equality are also relatively equal. Equality is not the same, so it does not mean that they will get exactly the same result. To ensure equality in education, we need to confirm that the direction of changes is towards equality. Educational equality is not absolute. For example, in a multiplayer game, it needs to ensure that each player has equal conditions at the beginning, together with the same game interface, character attributes and equipment. But there is no way to control that every player has the same computer configuration, game technology or logic strategy, and the equality of these conditions is the premise for these players to compete fairly.[1]

The concept of educational equity has a long history, the pursuit of which is an ancient concept of human society. Historically, Plato, a great thinker of ancient Greece, first proposed the idea of educational equity, while Aristotle first proposed to guarantee the educational rights of free citizens through laws. Two thousand years ago, Confucius, a great educator in ancient China, also put forward a simple educational democratic thought of "education without discrimination". In the late $18^{\text {th }}$ century, the idea of educational equity was transformed into legislative measures of some western countries, which legally confirmed that everyone had equal opportunities to receive education. The imperial examination system established in Sui Dynasty also embodies the idea of educational equity. In modern western society, there are three different views of educational equity in different periods, namely conservatism, liberalism and radicalism. In 1949, after the founding of new China, the new "national, scientific and popular" democratic education policy was established in the "common program", reflecting the basic value of new China's emphasis on social and educational equity.

Therefore, we can say that educational equity is a historical category [2], which has different meanings in different countries and historical periods. It is not only a reflection but also a transcendence of social reality, which is the unity of social reality and educational ideal with a specific historical significance, including its historical rationality and historical limitations. (1) To ensure that everyone has equal rights and obligations to receive education; (2) To provide relatively equal opportunities and conditions for receiving education; (3) To achieve relatively equal opportunities and effects of education, that is, each student can reach the most basic standard after receiving education of the same level, including substantive fairness in students' academic performance, fairness in education quality and equality in goal level. Among them, "to ensure that everyone has the opportunity to receive education" is the premise and foundation, "to provide relatively equal opportunities and conditions for education" is the further requirement, which is also the premise of " opportunities for educational success" and "a relatively equal educational effect". Generally, these three levels are summarized as: starting point fairness, process fairness and result fairness [3].

In addition, a correct understanding of educational equity also includes: there is a certain relativity in the development of educational equity, and the pursuit of educational equity is unified with that of educational efficiency. From the perspective of educational practice subject, educational equity can be divided into students' equity and teachers' equity. Students' equity refers to the issue of treating and evaluating students' equity, while teachers' equity refers to the issue of treating and evaluating teachers' equity. [4]

From the perspective of educational activity process, it can be divided into educational starting point equity, process equity and result equity. Fairness at the starting point means that everyone has the opportunity to start his or her learning career without the influence of gender, race, origin, economic status, living environment or other conditions. Process fairness means that everyone is treated equally during education on both subjective and objective aspects. Result equity means an equal quality of education.

From the point of view that the result of educational equity is based on certain principles of equity, educational equity can be divided into principle equity, operation equity and result equity. The principle of educational fairness is the precondition of educational result fairness. To achieve the fairness of operation, the operation steps need to be rationalized, fixed and form a fair procedure [5]. It also needs supervision mechanisms, 
supervision institutions and supporting technical means of various forms to ensure the fairness of results.

Whether the subject of educational practice (educator and educatee) is regarded as different or not, educational equity can be divided into homogeneous and different educational equity. Homogeneous educational equity means neglecting the differences among people and guiding the actual educational activities based on the same educational equity principle. It is thought by the difference of educational equity that everyone is different.

From the point of view of existence and concept, what we are talking about above is existence fairness. In addition, there is also idea level fairness in education fairness, which is a subjective reflection and a value judgment of existence fairness. It is mainly manifested as a sense of education fairness, that is, a psychological feeling when evaluating fairness. In fact, after entering the $21^{\text {st }}$ century, the western academic circles put forward a view that "giving everyone equal opportunities does not mean nominal equality - equal opportunities, but is to ensure that everyone can receive appropriate education, and the progress as well as methods of this kind of education are suitable for everyone's characteristics", which means that educational equity is to maximize students' access to knowledge education and highlight the personality of students as individuals.

In the document prepared by the Organization for Economic Cooperation and Development (OECD) in 2007 for the purpose of assisting its member countries in formulating education policies, the definition of educational equity is that: "educational equity contains two meanings. The first is fairness, which is to ensure that personal and social factors such as gender, socioeconomic status and race do not hinder people from reaching the educational height allowed by their ability. The second is coverage, which is to ensure that all people receive basic and minimum-standard education for example, everyone should be able to read, write and do simple arithmetic. "This also means that educational equity is to "teach students in accordance with their aptitude" to make people fully developed, and to ensure that all people receive the minimum-standard education. Educational equity is not equal or an equal distribution of educational resources. It also means that it is against the principle of educational equity to include gender, socio-economic status and other personal as well as social factors into the admission standards, so that these factors keep some students out of the school gate and hinder their development; and the admission standard that "everyone is equal in front of scores" is in line with the principle of educational equity.

\section{DISCUSSION}

\subsection{Problems in education}

\subsubsection{The imbalance of educational resources}

With the rapid development of social economy, people have higher and higher requirements for the quality of education, which is embodied in the fairness of education. Whether in urban or rural areas, developed areas or poor areas, people want to get the same educational environment and resources. Due to the imbalance of regional economic development in China, there is a gap between urban and rural areas, developed areas and poor areas in the starting point, process and result of education. In the field of higher education, this regional difference is particularly prominent. China's higher education resources are concentrated in the developed coastal areas. Among the top 100 universities, 63 are in the East and 12 in the West. According to the practice of higher education enrollment in China, the number of college students will be inclined to the location of the school every year, and the main source of students is from the local. Therefore, the eastern region with more colleges and universities can enjoy more higher education resources. The distribution and enrollment of Regional Universities in China in 2015. For a long time, in the face of limited educational resources, whether in terms of policy or capital, China's investment in Colleges and universities in the eastern region is higher than that in the western region. This has exacerbated the gap between the eastern and western higher education, thus affecting the improvement of China's higher education level as a whole. From the provincial perspective, under the same achievement, the eastern students who have the registered residence in Beijing and Shanghai have much more opportunities to get universities than other provinces. The number of colleges and universities in China and the proportion of enrollment in 2015. Although the state's investment in education in economically underdeveloped areas is increasing year by year, due to their weak economic foundation, these areas cannot well guarantee the conditions of some schools, and some even cannot meet the needs of the most basic teaching and learning conditions. Some students can't afford to go to school, or even can't go to school. In addition, due to the poor natural conditions, many excellent teachers do not want to come, are not willing to come, and even cannot stay, resulting in education software and hardware cannot achieve fairness.

\subsubsection{The limitation of traditional education}

The traditional teaching aims at task, tool and benefit. In the context of exam oriented education, teachers' teaching task is often to strengthen students' cognition, through repeated indoctrination, increasing 
the amount of homework, and endless examination means, external pressure drives students to master knowledge and complete teaching objectives. Teachers expect students to learn according to the design of the teaching plan and answer questions according to the teaching reference answers. Students play the role of teachers in completing the teaching plan in class, and class becomes the stage for teachers to perform "teaching plan play". Teachers only pay attention to the enrollment rate and treat all students in the same way. As long as they can promote students to a good school, they will think that they have achieved the teaching goal, and their achievements become the standard to measure the quality of students, often ignoring the individual differences of students. For students' independent thinking and innovation consciousness, teachers often do not pay much attention to it, to some extent, the students' personalized development is lost, which leads to the unfair phenomenon of education.

\subsubsection{The influence of higher education charge system}

At present, except for military cadets, free normal students and free medical students, other majors in China's higher education have to charge tuition fees in order to reduce the pressure of the increase of higher education costs. Although schools share the cost of education to a certain extent, expand the enrollment scale, enrich the teaching resources, which is conducive to the realization of educational equity from a strategic point of view, the increasing tuition fees for low-income families have reached or exceeded the affordability. According to China Statistical Yearbook 2017, in 2016, the proportion of rural population was $42.65 \%$, the population was 589.73 million, and the number of rural poor people in China was 43.35 million. It can be seen that China's rural poor still account for about $7.35 \%$ of the rural population. Although China has proposed to eliminate poverty by 2020 , it still needs some time and process to fundamentally solve the poverty problem. The increasing high tuition and living expenses make low-income families flinch. In addition, with the increasing pressure of College Students' work, many families choose to let their children get employment as soon as possible, which makes some children who are supposed to go to higher education institutions lose the chance to go to university.

\subsection{The merit exhibited by education-based informatization for improving the fairness of fundamental education.}

Educational informatization essential aims at developing an overall service system by employing the Internet to be the critical component and boost the extensive use of information technique in a wide aspects of society, in particular the extensive use of information technique for fundamental education. Educational informatization refers to a feasible method for boosting the fairness of fundamental education, as well as the only approach in terms of China's fundamental education for moving to fairness.

\subsubsection{Achieve resource sharing and equivalent chances}

Information technique exhibits incomparable merits for resource allocating in contrast to the conventional manner, i.e., breaking down time and space limits and the high-speed information flow. As assisted by multiple-media and network technique, the monopoly scenario of education resources can be broken by several areas and schools. Thus, education and teaching resources with high quality can be shared, and all educatee can acquire the identical chance for enjoying educational resource with high quality. On the whole, education equity falls to 3 levels: starting point, equivalent process and equivalent result. To a certain extent, distance education is capable of reducing the conflict of equivalent result, equivalent process and equivalent starting point. If the fundamental conditions are satisfied, the relative fairness of education and result can be achieved. Timely compensatory education can be offered to the student disadvantaged so that they can get fair education effect.

\subsubsection{Facilitate personalization-based learning and teaching}

Education equity upholds the full respect of the individual's right for selection and endowing individuals the chance for selecting the education they require. The existing classroom teaching mode here cannot effectively realize personalization teaching, whereas educational informatization is capable of fulfilling the mentioned goal. It is capable of making learners select the things they require in accordance with their interests based on considerable resources of education-related information, but also build a cross interactive communication platform between students and teachers as assisted by information network for realizing personalization-based teaching and learning. For instance, according to the Chinese classroom, teachers are able to exploit information-relate data and information for stressing learning dynamic state and regulations of students timely, primarily covering various expression approaches of students, idea and study result related to texts. Besides, teachers are capable of encouraging and praising students holding original opinions timely, correcting students with misunderstanding and deviation timely, and supplementing students requiring overall and prominent real-time improvement, for achieving personalizationbased learning and teaching. 


\subsubsection{Enhance teacher training level and quality}

As assisted by modern distance education technique, multiple-level and standard teacher training in a wide range of regions is capable of breaking the time and space limits, developing a platform for industry cooperation in teacher education, building and sharing fundamental education resources with high quality, elevating teacher training's quality level and feasibility, and providing possible chances for teachers exhibiting various actual experience and teaching and learning styles (e.g., teachers within remote regions). Thus, their economic burden can be significantly reduced. As a result, overall learning opportunities can be obtained for the improvement of teachers' professional knowledge and skills.

\subsubsection{Ways to promote educational equity by using network education.}

Educational equity can promote social and economic development, cultural prosperity and political democracy, but as a part of social equity, it is also affected by social economy, culture and politics. With the continuous progress of society, people not only want to enjoy the most basic education resources, but also enjoy higher quality education resources, especially the idea of universal education and lifelong education. As a new education mode, in the process of realizing social and educational equity, network education is more conducive to reflect its value. In today's world, with the continuous development of new technologies such as cloud computing, big data and Internet, it is possible to use online education to promote educational equity.

(1) Expand the coverage of online education and enhance the awareness of civic education fairness

Pascal mentioned in the book of thoughts that "man is a reed that can think", and values dominate all human actions. In order to realize educational equity through online education, we need to enhance the equity awareness of the whole people. According to the 40th statistical report on the development of Internet in China and the Research Report on the development of rural Internet in 2015 released by China Internet Network Information Center (CNNIC) in Beijing, as of June 2017, the number of Internet users in China has reached 750 million, and the Internet penetration rate is $54.3 \%$. As of December 2015, the scale of rural Internet users has reached 195 million, and the Internet penetration rate has reached $31.6 \%$. In addition, $62.3 \%$ of the non internet users are rural population, accounting for $68.4 \%$ of the total rural population in China, while $34.2 \%$ of the non internet users are in urban areas. The above data show that there are differences in the penetration rate and utilization rate of network between urban and rural areas, and there is also a gap in the starting point of receiving network education. As a big country with a large population and significant differences, we need national macro-control, rational allocation of resources, and increase the investment in network education in rural areas, so as to narrow the gap between urban and rural areas and realize the fairness of education starting point. As of 2013, a total of 68 Modern Distance Education Pilot Universities in China have carried out online higher diploma education, and the number of students enrolled, enrolled and graduated in online education is increasing year by year. From 2014 to 2016, the enrollment number of online education, the enrollment number of ordinary colleges and universities, and the proportion of online education enrollment personnel in the enrollment number of ordinary colleges and universities. Although the enrollment proportion of online education has decreased slightly in the past three years, the overall enrollment of online education is increasing, the number and scale of higher education are expanding, and people's awareness of the desire to enjoy high-quality education resources is increasing. Only when citizens have the awareness of education equity, can they fight for the right of education equity, have the power to participate in the formulation and reform of education equity policies, and improve their competitive strength through online education.

(2) Strengthen the sharing of educational resources and improve the learner's starting point diagnosis

Learning is a gradual process of continuous accumulation, and knowledge itself has a logical relationship from simple to complex. Teaching is actually a process in which teachers transform the knowledge structure of teaching materials into students' cognitive structure. In view of the different characteristics of the knowledge and ability reserve of elearners when learning new knowledge, teachers should strengthen the diagnosis of e-learners' learning preparation and try to eliminate the differences of the starting points of e-learners. Educational resources are an important factor affecting the transformation of knowledge structure. Teachers should provide different online learning resources for different students in the same learning environment, try to make up for the differences of students' learning starting points, and let each student get the same learning results. At the same time, the state should increase investment in online education, provide high-quality education resources, build a humanized online education platform, so that each learner can learn the latest theoretical achievements on the basis of unlimited time and space. In the government work report in March 2006, Premier Wen Jiabao clearly pointed out: to promote education equity, public education resources should be tilted to rural areas, central and western regions, povertystricken areas, ethnic minority areas, weak schools and students from poor families. The Beijing University 100 project of Guangdong Province is the best example of online education promoting educational equity. 
(3) Improve the level of network moral cultivation, better play to the advantages of network education

Stanford University President David Jordan once said: "our goal is to make students not only have the knowledge and skills to do things, but also have the wisdom to know what to do." (Bai Xue, 2014) In a free and open virtual world, people with internet skills may have both positive and negative effects on society. In the process of network education, some learners are easy to lose themselves in the mixed network world and lead to concept deviation due to the lack of moral emotion, imperfect cognition and anomie behavior. Therefore, it is also a compulsory course to improve citizens' network moral cultivation. On the one hand, in the face of rich and colorful Internet resources, learners should have the ability to identify information and constantly improve their information literacy. On the other hand, high-quality network education needs educators with superb teaching skills and high-quality information literacy to implement. Excellent educators can make use of the network education platform to play their own advantages, which plays a very important role in cultivating talents with good morality and high quality.

\section{CONCLUSION}

To sum up, the issue of educational equity in today's world still faces many challenges. For example, the unfair distribution of educational resources and the limitations of traditional education. Therefore, we can give full play to the advantages of e-education, optimize the allocation of educational resources, and help realize educational equity as soon as possible.

\section{REFERENCES}

[1] On the activating role of teachers' coaching role in online teaching $[\mathrm{J}]$. Huang Zhigang. Research on curriculum education. 2017 (28)

[2] Analysis on the mode of applying distance education network to history teaching [J]. Zhang Lufeng. Examination weekly. 2017 (15)

[3] On network teaching and quality education [J]. Zhao Yuxia, Xu Chao. Modern education science. 2004 (12)

[4] An overview of dance courses on network teaching platform [J]. Liu Lin. art and technology. 2019 (03)

[5] Analysis of the complementary relationship between network teaching and traditional teaching [J]. Bai Xue. Modern women (latter ten days). 2014 (11) 